\title{
DRIVING FUNCTIONS FOR URBAN SUSTAINABILITY: THE DOUBLE-EDGED NATURE OF URBAN TOURISM
}

\author{
R. FISTOLA ${ }^{1} \&$ R.A. LA ROCCA ${ }^{2}$ \\ ${ }^{1}$ Department of Engineering, University of Sannio, Italy. \\ ${ }^{2}$ Department of Civil, Architectural and Environmental Engineering, University of Naples Federico II, Italy.
}

\begin{abstract}
Our concept of urban sustainability is changing along with our evolving modern society. It is related to a number of factors that have an impact on our current understanding of the concept of an urban system. Referring to a systemic approach to understanding the urban system, we can consider urban sustainability as the opposite of urban entropy, which represents both the "dark side of the urban system" and the negative component of each urban subsystem. Within these subsystems, we can identify some driving functions that play an important role in urban sustainability. Nevertheless, when these functions exceed the threshold of urban load, urban entropy increases exponentially. Starting with the very recent changes in urban entropy (as well as urban sustainability) and by assuming that the negative components of the urban system are connected to urban risks, two types of urban entropies can be defined: endogenous and exogenous. The first relates to internal conditions of urban subsystems which unplanned urban management can generate. The second one relates to external causes: natural and anthropic. Within this framework, tourism can be considered as one of the urban functions affecting the organizational process of an urban system. Tourism depends on internal factors and grows by generating exogenous flows. In many cases, tourism plays a fundamental role in an urban economy and it acts as a strategic factor for urban competitiveness. When tourism exceeds urban capacity, it causes urban malfunctions. In this sense, tourism is one of the most sensitive urban functions regarding the process of entropy. Using the systemic approach as a theoretical reference, this paper states that tourism can act as a driving function able to shift the urban system towards sustainable condition if it is integrated into the process of town planning.

Keywords: systemic approach, tourist city, urban entropy, urban tourism.
\end{abstract}

\section{THE DOUBLE-EDGE NATURE OF TOURISM}

The connection between tourism and the city is complex. Cities are physical places where the needs of tourists and inhabitants intersect. This means that cities must face different demands by offering adequate structures and facilities.

This condition characterizes the tourist cities and may be representative of their vulnerability. The tourist demand, in fact, can be considered as an additional urban load that can compromise the balance of a city organization affecting its urban quality of life. Nevertheless, tourism is seldom studied as an intrusive activity because of its indisputable positive economic effects.

The relevance of the key role of tourism on urban economies prevails over a consideration of the impacts that it generates on an urban environment as well as on the general organization of a city and on the socio-anthropic system in terms of conflicts between residents and tourists. 
In this study, the double-edged nature of tourism refers to the ambiguity of tourism in that it is both an economic resource and a generator of negative impacts (overcrowding, pollution, noise, soil and energy consumption) on urban systems. The second aspect concerns town planning more directly, if we consider that the efficiency of a city also depends on the quality of services and infrastructures composing the urban supply.

This could be better understood if we thought of tourism as a system comprising two main components: the demand-side and the supply-side. On one side, tourism demand concerns the needs expressed by a non-residential population. On the other side, tourism supply refers to the presence of facilities and structures in the city to satisfy this demand. Town planning can influence the demand-side by intervening on the supply-side in terms of quantity, distribution and qualities of facilities and structures in order to assure the efficiency of the city.

In other words, the urban planner's challenge consists in defining the conditions (policies and strategies) and the technical tools required in order to provide a qualified urban supply (of services, spaces and facilities) that has to be compatible with urban characteristics and resources. In this sense, tourism planning and land-use are closely connected and, if properly planned, tourism can be a driving function to lead the urban system towards a more sustainable dimension.

The adoption of a systemic logic allows us to propose an innovative approach to the study of the relationship between tourism and the city.

\section{THE CITY AS A SYSTEM}

Considering the multiple phenomena of perturbation currently affecting the human settlements of the planet, it is clear that cities - which represent the physical locations where the future of the planet will be decided - have to be interpreted through paradigms that will be able to take into account non-linear trends, events with high incidence of imbalance and entropic processes. Nowadays, these processes are undergoing an exponential growth.

Moreover, considering the systemic entropy that currently characterizes our human presence on the planet and which catalyzes events such as an economic and financial crisis, climate change, a growing social conflict, an energy problem, etc. it is clear that the science of complex ecodynamic systems [1] appears currently to be the only scientific reference, which is usefully adoptable, able to correlate strongly interacting elements in the current urban dynamics and able to take account of potential stochastic evolution of the city system, hardly understandable by adopting other interpretive paradigms. Furthermore, complexity theory seems to be the only way to discover a common code inside the mechanisms of the universe [2] and of the city, as well.

A number of cities are today in a deep structural crisis due to economic, social and functional problems. By applying a systemic approach [3] to the study of the city, it is possible to analyse the different urban components and the factors responsible for this crisis. Considering the city as a complex evolving system, it is possible to define an entropic condition in which the system can fall on its own accord during its evolution. This entropic state affects all urban subsystems but in a different way in terms of peculiarities and intensity. Considering that urban subsystems are components of the whole city, it is possible to focus on identifying which of these are responsible for the major amount of the entropy and, consequently, to set up a more effective urban policy to implement in the city. As is well known from urban literature, the systemic approach could be considered the most useful way to understanding the evolution, transformation and state of an urban system. Thanks to this approach, the city could be interpreted as a complex dynamic system and a number of seminal studies have been conducted on this topic. 
Interpretation of the city as a complex system is very useful in order to envisage the future state of the urban system and the capability to identify a large number of urban subsystems that are components of the city from a holistic point of view. As mentioned in previous studies [4], it is possible to distinguish some urban subsystems that could be clusterised as "generative" subsystems and others that can be enclosed in a set called "generated". The first cluster contains subsystems such as the social-anthropic subsystem and the geo-morphologic one. These two subsystems contain the bio/anthropic component and the land/environmental component of the urban system. These subsystems are the main components of the urban system as a whole and from these subsystems are born others that one can reasonably call generated urban systems. The physical subsystem has the built space of the city as its main component. Furthermore, the functional subsystem is structured by urban activities. The last one is the most affected by entropic phenomena.

\section{TOURISM AS A RESOURCE OR AS AN ENTROPIC FUNCTION}

Thinking in a systemic framework makes it possible to envisage that all the subsystems are connected to each other and that they interact simultaneously. The change of status of a part of one of them determines a change of the entire subsystem that produces a domino effect of mutation on all the others and, consequently, on the entire urban system. The structural crisis is due to a generation of entropy in one of the subsystems that is transmitted, with a propagation amplified chain, to all the others and to the whole city. In normal conditions, the urban system evolves inside a sustainable range of development, where the production of entropy is under control (Fig. 1).

For an endogenous malfunction in its parts or in its structure, a subsystem could be characterized as an "entropic" generator and to provoke a chain of damage that, by reducing its complexity through the destruction of relational structures [5] can lead to a collapse of the whole urban system (Fig. 2). It is, therefore, possible to relate the urban crisis to the generation of entropy that originates inside of the subsystems; among them, the functional subsystem is the much more sensitive one to this phenomenon. The entropic crisis can be similarly cata-

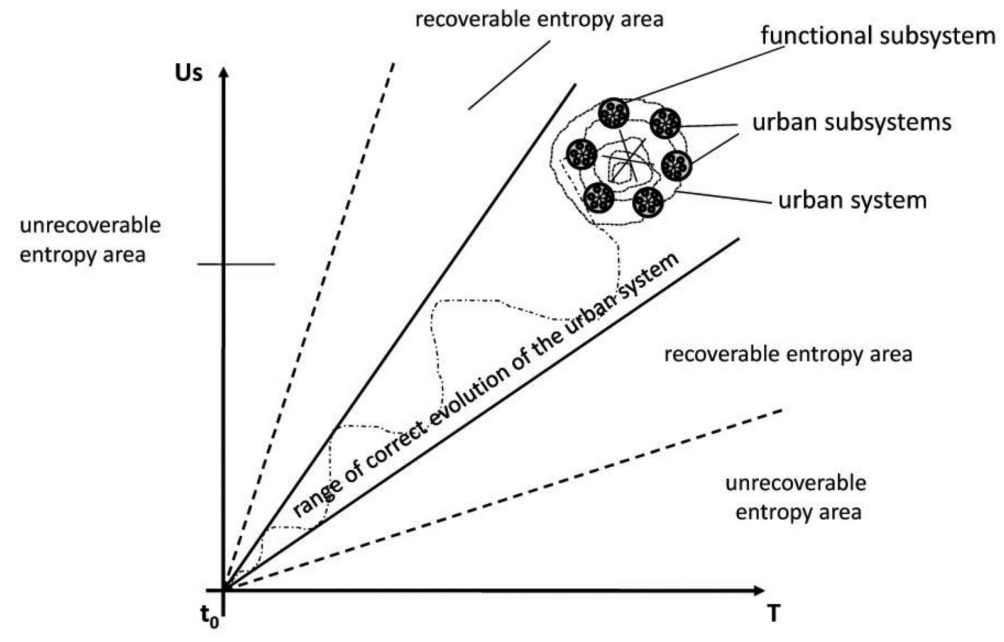

Figure 1: The urban system (made up of urban subsystems) inside the range of correct (sustainable) evolution described by status on the $\mathrm{y}$ axis and time on the $\mathrm{x}$ axis. 
72 Urban Regeneration and Sustainability

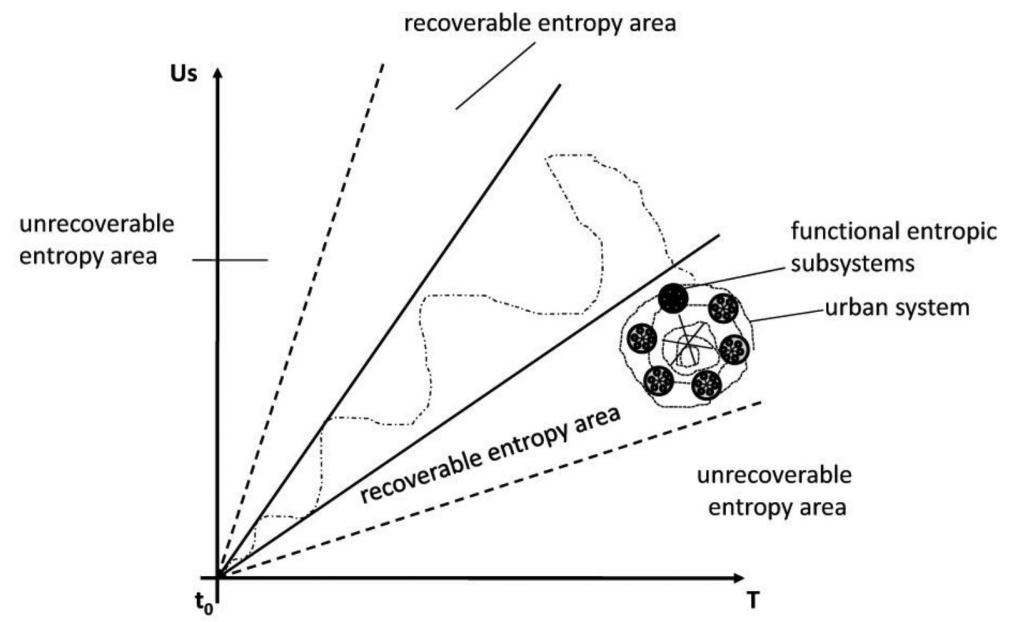

Figure 2: The functional subsystem affected by entropy drives the entire urban system towards the entropy zone making it necessary to use new resources to recover the system.

lyzed by an exogenous factor to the urban system that comes from the meta-system, and also in this case, acts primarily on subsystems of higher vulnerability as the functional system. The activities of a functional system can then be elements of evolutionary propulsion, when acting properly inside the city, but can become entropic generators if affected either by endogenous dyscrasias or by external forces from a meta-system.

Tourism is probably the most emblematic urban activity of this phenomenon. For many cities across the world, tourist activity generates a large percentage of the economic base of the city and all other urban functions are interconnected with it (trade, mobility, residence, etc.). When the tourist activity becomes too invasive in the city, it generates those entropic processes that progressively lead the city towards a slow degradation. It is possible to identify this process as the "urban ousting", which occurs when excessive numbers of tourists invade the urban space and they become "entropic city users".

Urban ousting may occur in a "partial" way when, within the city, particularly important but temporally limited events are held such as: sporting events, shows, fairs, etc. that determine, at times, the closure of entire urban quarters or even in a "total" way, when the tourist polarization is so high that it even causes a shift of residents. This is evident in particular urban contexts, for example in cities like Venice (Italy). It is, therefore, necessary to manage the tourism phenomenon appropriately in order to avoid leading the urban system towards an entropic status. While aspiring to find some non-entropic policies in order to manage the urban tourism phenomenon, it seems necessary to group a classification of the different types of cities, considered with regard to the characteristics that determine a particular tourist polarization.

\section{THE TOURIST ESSENCE OF A CITY: A TAXONOMY FOR URBAN MANAGEMENT}

The classification of tourist cities (even though not exhaustive) can be a useful tool to analyse the relationship between tourism and an urban context. It can also help to define policies aimed at reducing urban entropy, in particular when an urban system is a tourist city. 
With this objective in mind, we first indicate the causes that make cities a "tourist destination".

In the history of tourism, cities have always been favourite destinations. For tourists a city represents an unsurpassable opportunity for cultural, economical and relational enhancement. We can state that urban tourism is generated from this legacy, becoming an object of research in the past two/three decades [6-8].

Based on the spread of urban tourism, many cities have converted their own image into a tourist destination even though in some cases they had never had such an entity (Torino, Milano, Bilbao, Essen, Liverpool, Glasgow, Baltimore, Berlin, etc.). In this context, tourism acted as a catalyst of interest for many cities. On the other hand, cities, according to market logic, began to propose their resources as a "product" generating a demand (tourist demand). The ability to make resources accessible and to communicate them as attractive factors (the supply-side of tourism) is the element that triggers the process of conversion of a region in a "tourist destination." In this conversion, cities became a favourite tourist destination because of their multifunctional nature. Cities do indeed converge a multiplicity of factors that attract tourists; these factors not just serve as physical elements (monuments, historic centers, cathedrals etc.) but also offer the possibility for tourists to take part in events and occasions that can make their experience unique. The combination of these elements makes the city an exclusive "sensible" tourist destination. Sensibility refers to the need of managing the tourist flows in the city in order to reduce danger of the urban system falling prey to entropy conditions.

The need to manage tourism in cities is an object of discussion that has also been referred in recent scientific literature, [9-12]. Nevertheless, there is still a lack of interest in considering the management of urban tourism as part of city planning, of transport design, or urban regeneration policies (where most of the local tourism strategies take place). Some researchers in the tourism sector agree in promoting a holistic approach to deal with both urban management and destination management as they both relate to an urban system [13].

Until now, the emphasis has been laid more on the promotion of tourism rather than on the definition of strategies and policies aimed at integrating the exigencies of development with the need of preserving territorial resources.

Urban planning (by which we mean the search for an order through a plan) in tourist cities should be addressed towards integrating urban marketing and governance. The integration between these two intrinsically related interests is essential to promoting sustainability in cities, and particularly in tourist cities. Being a diffusive and an inter-sectorial activity, tourism can be the means to promote sustainable models of the city and its resources, therby improving change in visitors behaviour (more attention to energy and water consumption, to waste generation, to promotion of soft mobility etc.).

In the context of these considerations, the proposal of a classification is the first attempt to analyzing the complex relationship between tourism and the city, highlighting how the tourism function may play different roles within an urban organization.

Making a typology of cities with high tourist vocation is not as simple as tourists using a city for different purposes (leisure, holiday, cultural, business and so on). Still, it is possible to classify a tourist city on the base of the relationship it creates between tourist trends and the city itself.

We start from the classification of Buhalis [14] and go beyond the goals of promotion of the tourist destination by introducing the issue of governance of tourism as an urban phenomenon in order to control the causes that can lead to an entropy condition. We consider that the "tourist cities" can be classified into four main types: 


\section{Urban Regeneration and Sustainability}

- emblem cities,

- scattered supply cities,

- mono-polar cities,

- niche cities.

Emblem cities have been considered as those destinations whose attractiveness strongly depends on their uniqueness. Tourism function prevails over everyday urban functions and can represent a real threat of exceeding the level of the carrying capacity of the city. The concentration of tourist demand inside a city jeopardizes the balance of the total urban system and in this sense, the city-tourism relationship is heavily skewed. The main risk consists in the denaturalization of ordinary urban activities. Urban economy bases are exclusive activities that offer services related to tourism and this is detrimental to handicraft activities connected with the history and culture of the city. These cities are economically dependent on tourism and they are struggling to withstand the massive load of tourism. The most representative example of such a case is the city of Venice in Italy, or Barcelona in Spain where conflicts between tourists and residents occur. In these cities, the resident population does not share tourism development policies, and suffers from the increased cost of living. The effect on resident population consists mainly of a gentrifugation due to cost polices and to the massive load of tourism (the "urban ousting" is that residents gradually move farther and farther out of the inner city towards places that are less crowded and have a lower cost of living) (Figs 3 and 4).

Scattered supply cities have been defined as cities characterized by the diffusion of different important attractions throughout the territory, which are available and are able to satisfy diverse segments of tourist demand. In these cities, the tourist function has an important role in that it distributes its goods in different urban zones and makes particular use of the most historically representative areas of the city. Tourist movement in many places is concentrated only during certain periods of the year or during certain special occasions or events. There can also be cities that do not have an embedded tourist vocation and have only recently converted their urban image. The Italian city of Turin can be a significant example

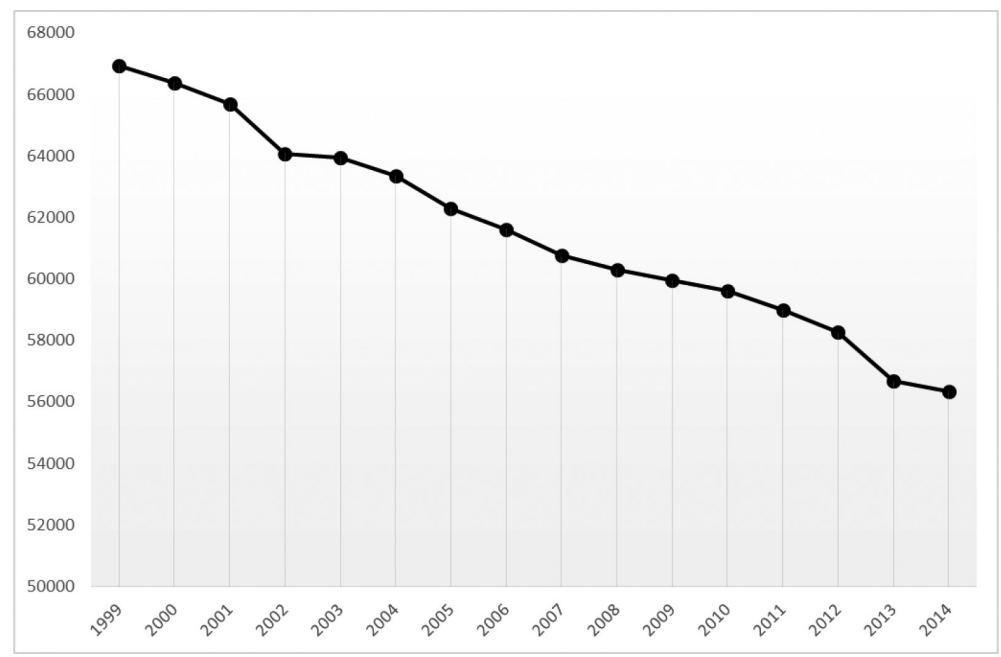

Figure 3: Resident population in Venice from 1999 to 2014 (elaboration on Regional Tourist Office Data 2015). 


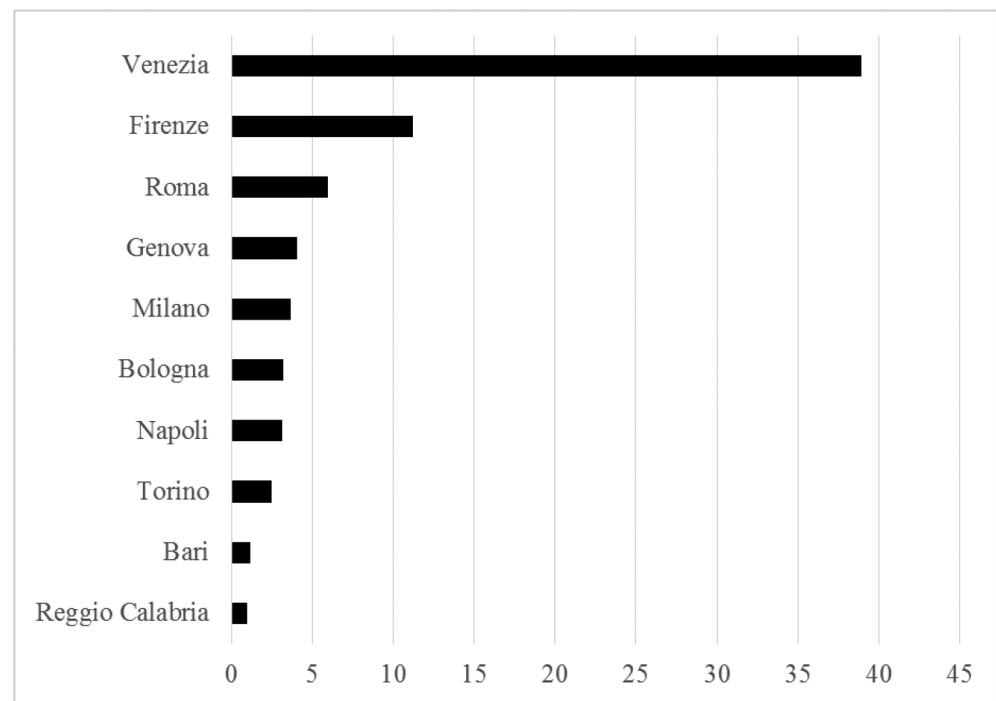

Figure 4: Tourist pressure (Tourist presences and resident population ratio) in the Italian Metropolitan Areas (elaboration on Istat data 2013).

of this typology of tourist cities. This city has reconverted its image (from a city that was a symbol of industrial production) rediscovering its historical heritage and proposing itself as a cultural tourist destination. This change resulted also in the nomination of Turin as the location for the 2006 Olympics, which set off the process in which large urban areas were reconverted while maintaining the dynamic relationship between the city and tourism.

In mono-polar cities, the tourist function is almost exclusively centered on a single pole of attraction and it is concentrated in the place where this attraction is found. The system of services is specialized and is aimed at a specific segment of demand. An example of this typology can be found in cities that are interested in promoting religious tourism (Lourdes, Assisi, San Giovanni Rotondo, Fatima), which is an evolution of original sites of pilgrimage.

Other examples of this typology are seaside cities and mountain ski resorts where tourist activity has strongly characterized the urban asset and its development. Local economies are totally based on tourism and they are often the result of an investment strategy exclusively oriented to tourism development.

The niche cities (villages, small urban cities) represent an emerging segment in urban tourism. In this case, the tourist function rarely reaches the point of excess and is activated by various elements of attraction that are connected with local tradition. This city is in contrast to the model of mass tourism destination proposing cities as "excellence poles" of a network and is aimed at promoting territorial identities. The relationship between tourism and the city in this case, probably more than any other, focuses on the interaction among different organized poles of tourist supply that interact with each other. The Slow City Movement can be representative of this typology, underlining the need to improve alternative models of tourism and make use of the city [17].

The proposed urban "slow model", in fact, refers to the medium- to small-sized cities $(50,000$ inhabitants) where it is possible to take on an alternative lifestyle. The main challenge consists in applying the concept of slowness to the city where, on the contrary, there is a prevalence of the concept of speed as a means to maximize efficiency. 
76 Urban Regeneration and Sustainability

\section{FROM TOURIST ESSENCE TO URBAN PLANNING}

Integration between tourism and town planning is a difficult task, as there are different levels of responsibilities and purposes of the public sector as well as of the private sector [15]. Nevertheless, some hypotheses of policies that can be adopted can be formulated according to the previous (not exhaustive) taxonomy proposed and in order to achieve a balanced status, even though dynamic, for the urban system. In particular, we refer to the definition of interventions that have to be framed within the objectives of:

- restraint policies,

- policies for the management of tourist flows,

- participation planning policies.

In the first case, interventions have to consider the need wherein the maximum capacity that an urban system can sustain cannot be exceeded. These measures can include also demarketing actions [14]; that is, the introduction of limitations in using the most sensitive urban areas (monuments, historical centers, archeological sites etc.). This aspect has to be considered in the definition of a local urban master plan where the distribution of the urban charges have to be decided by planning the supply-side elements (urban services and facilities).

In the second case, policies should also consider visitor management techniques to distribute tourist flows inside the city diverting them from more congested attraction areas to alternative paths of visiting the city. Sensitive areas of the urban system should be considered "protected areas" where some restrictions may be applied in order to reduce the impact of tourism. In particular, these measures should aim at:

- reducing the use of the sensitive areas (demand-side),

- varying timing and distribution of use (supply-side),

- improving action that can modify visitor behaviour (supply-side).

In the third case, measures have to consider the participation of all the actors (publics and privates) involved in the process of tourism development, wherein policy decision-making should be on a shared-approach basis. Such an approach permits reducing the conflicts that inevitably occur between tourists and residents and promotes more sustainable forms of tourism. The balance that can be attained among the diversified interests that the tourism development involves is dependent on the realization of an efficient system of governance. Governance in tourism is largely discussed in the scientific literature [16] and it mainly refers to the cooperation and partnership between public administrations and private stakeholders as the fundamental requisite for the success of a city as a tourist destination.

The proposed policies can be considered as first guidelines that can reduce the risk of generating dangerous entropic phenomena within the functional system (such as urban ousting), which could produce an entropic decay of the urban system as a whole.

\section{CONCLUSIONS}

The paper adopts a systemic approach to understanding how to manage the strategic urban functions that can drive cities either along a sustainable evolution or, on the contrary, towards dangerous conditions of entropy. Within the urban system, two types of entropies can be identified: an endogenous and exogenous. The first relates to internal conditions of urban 
subsystems, which unplanned urban management can generate. The second one relates to external causes that can be both natural and anthropic.

Among urban activities, tourism can be considered as a leading function that is capable of shifting the system towards one of the two opposite states. The double-edged nature of tourism, in fact, was attributed to its ambiguity of being, at the same time, both a positive factor of urban development and a generator of negative impacts on urban environment. Until now, the emphasis was laid more on the promotion of tourism rather than on the definition of strategies or policies aimed at integrating the exigencies of development with the need of preserving territorial resources. What this paper has tried to highlight is the conviction that tourism can act as a leading function capable of shifting the system towards more sustainable states if it is integrated into the process of urban governance. This is possible by managing the entropy that the evolution of the city generates considering the different typology of the tourist cities. Even though it cannot be considered exhaustive, the taxonomy proposed, thus, can be a useful tool with which to define adequate policies aimed at balancing the relation between tourism and the city. In search of this balance, town planning must play a strategic role, renewing its logics in order to evolve towards integrated processes of governance.

\section{REFERENCES}

[1] Prigogine, I., Le leggi del caos, Laterza, Bari, 2008.

[2] Chaisson, E.J., Using complexity science to search for unity in natural sciences. In Complexity and the Arrow of Time, eds. C.H. Lineweaver, P.C.W. Davies \& M. Ruse, Cambidge University Press, p. 68, 2013.

[3] von Bertalanffy, L., General System Theory, Penguin Books: Harmondsworth, 1972.

[4] Fistola, R., La città come sistema, (Volume II, Chapter 2). Per il XXI secolo una enciclopedia. Città cablata e nuova architettura, eds. C. Beguinot \& U. Cardarelli, Università degli Studi di Napoli "Federico II” (Di.Pi.S.T.), Consiglio Nazionale delle Ricerche (I.Pi.Ge.T.), Napoli, 1992.

[5] Fistola, R., Urban entropy vs sustainability: a new town planning perspective. In The Sustainable City VII., M. Pacetti, G. Passerini, C.A. Brebbia \& G. Latini, WIT press, WIT Transactions on Ecology and The Environment, 155, pp. 185-204, 2012. http://dx.doi.org/10.2495/sc120171

[6] Pearce, D.G., An integrative framework for urban tourism research. Annals of Tourism Research, 28(4), pp. 926-946, 2001. http://dx.doi.org/10.1016/S0160-7383(00)00082-7

[7] Ashworth, G.J., Urban tourism: still an imbalance in attention? In Classic Reviews in Tourism, ed. C. Cooper, Clevedon: Channel View, 2003.

[8] Ashworth, G. \& Page, S.J., Urban tourism research: recent progress and current paradoxes. Progress in Tourism Management, 2010.

[9] Evans, G., Planning for urban tourism: a critic of borough development plans and tpurism policy in London. International Journal of Tourism Research, 2, pp. 307-326, 2000. http://dx.doi.org/10.1002/1522-1970(200009/10)2:5<307::AID-JTR227>3.0.CO;2-5

[10] Pearce, D.G., Tourism development in Paris: public intervention. Annals of Tourism Research, 25(2), pp. 457-476, 1998. http://dx.doi.org/10.1016/S0160-7383(97)00096-0

[11] van den Berg, L., van der Borg, J.L.J. \& van der Meer, J. (eds), Urban Tourism: Performance and Strategies in Eight European Cities, Avebury, Aldershot, 1995. 
78 Urban Regeneration and Sustainability

[12] Law, C.M., Urban tourism and its contribution to economic regeneration. Urban Studies, 29, pp. 599-618, 1992.

[13] Pearce, D.G., Urban management, destination management and urban destination management: a comprarative review with issues and examples from New Zeland. International Journal of Tourism Cities, Emerald, 1(1), pp. 1-17, 2015.

[14] Buhalis, D., Marketing the competitive destination of the future. Tourism Management, 21, pp. 97-116, 2000. http://dx.doi.org/10.1016/S0261-5177(99)00095-3

[15] La Rocca, R.A., The Role of tourism in planning the smart city. TeMA Journal of Land Use, Mobility and Environment, 7(3), pp. 269-283, 2014. http://dx.doi.org/10.6092/1970-9870/2814

[16] Hall, M.C., A typology of governance and its implications for tourism policy analysis. Journal of Sustainable Tourism, 19, pp. 437-457, 2011. http://dx.doi.org/10.1080/09669582.2011.570346

[17] La Rocca RA From Sustainable City to Smart City. In Papa R. ed (2014) Towards Smart City a Scientific Approach, Aracne Editrice, Roma, ISBN 978-88-548-7024-6. 